\title{
Constraints on extensions of the Standard Model from precise electroweak data
}

\author{
John Ellis \\ CERN, CH-1211 Geneva 23, Switzerland \\ G.L. Fogli and E. Lisi \\ Dipartimento di Fisica di Bari, Bari, Italy \\ Sezione INFN di Bari, Bari, Italy
}

\begin{abstract}
We present an analysis of the constraints on one-loop "oblique" (vacuum polarization) electroweak radiative corrections imposed by precise data from LEP and other experiments. We present these constraints in full 3 -dimensional $S, T, U$ space, using a complete set of low-energy data, and LEP data on heary flavour production as well as leptons and hadrons. We take into account the uncertain top quark and Higgs boson contributions to non-oblique radiative corrections and discuss quantitatively rariations associated with higher-order effects. We compare our bounds with recent estimates in a number of different technicolour scenarios.
\end{abstract}

CERN-TH.6383/92

B ARI-TH.96/92

January 1992 


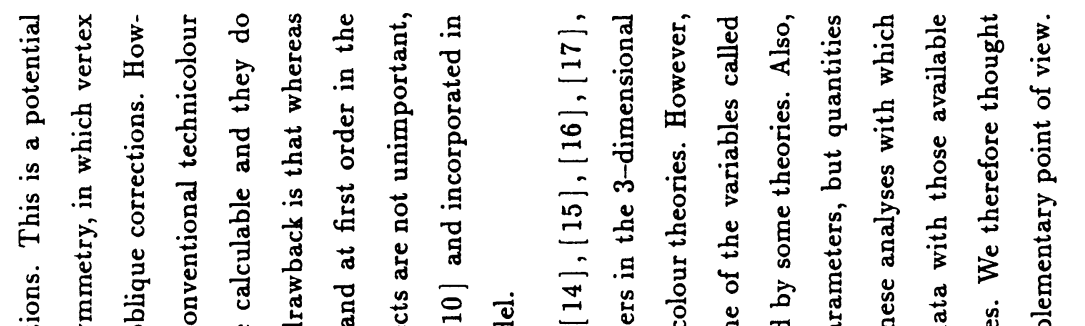

119.

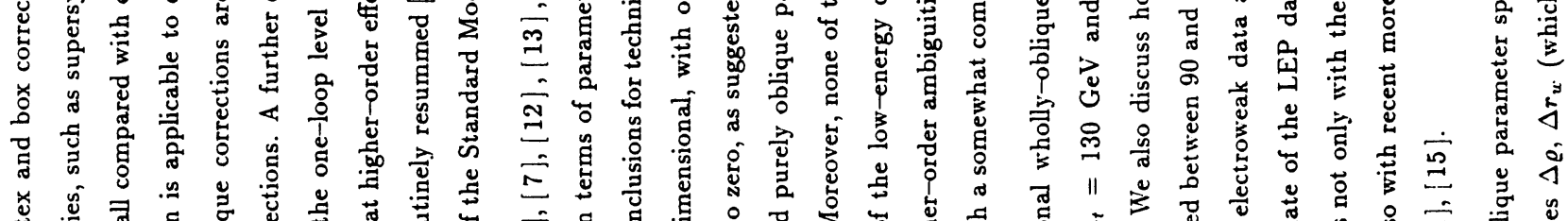
IIIIIII

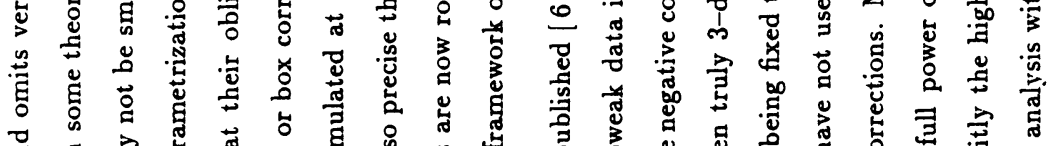

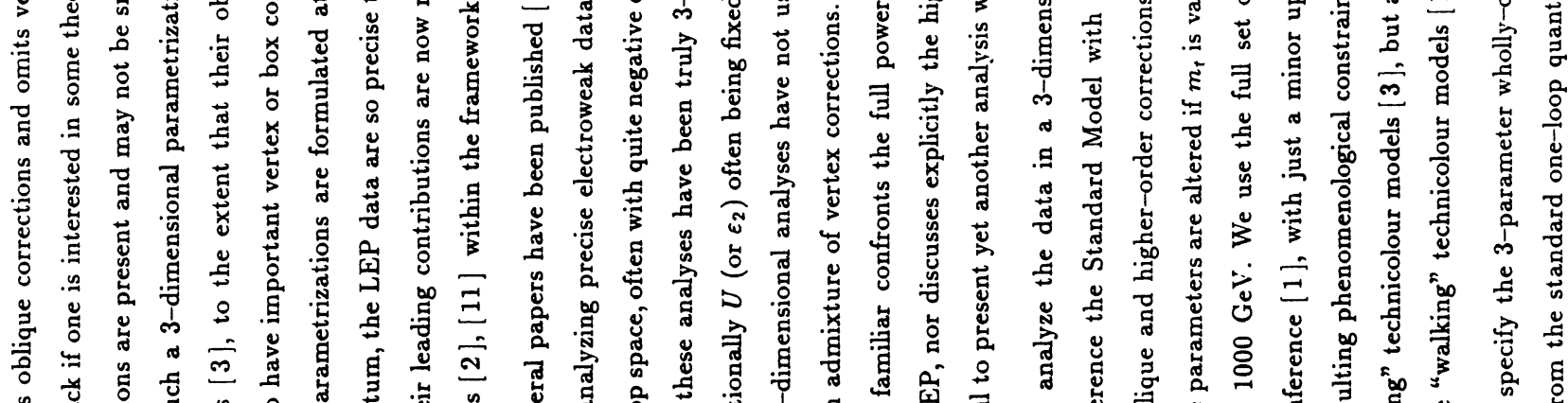

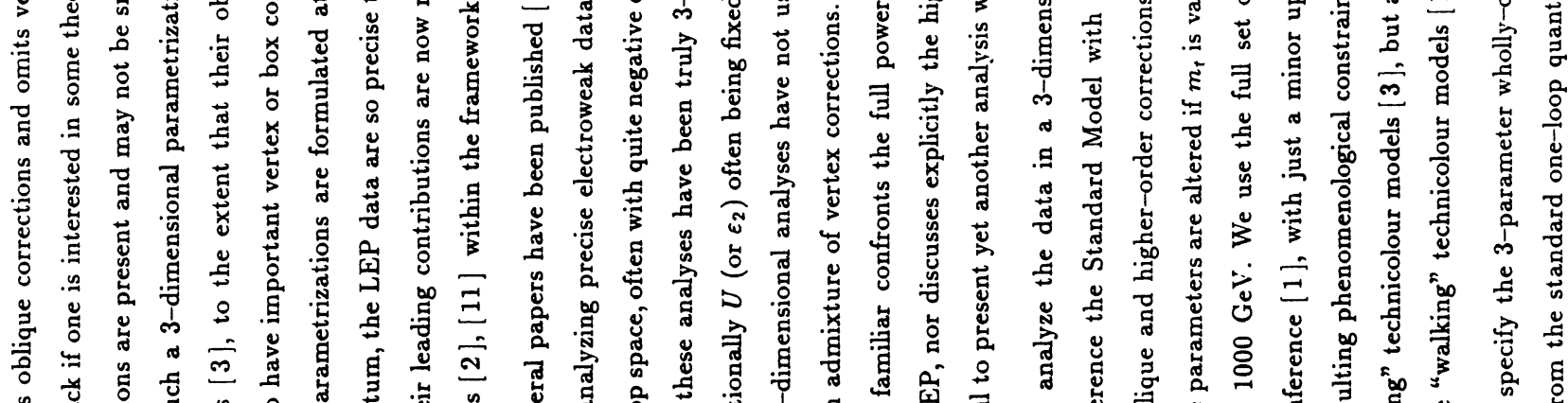

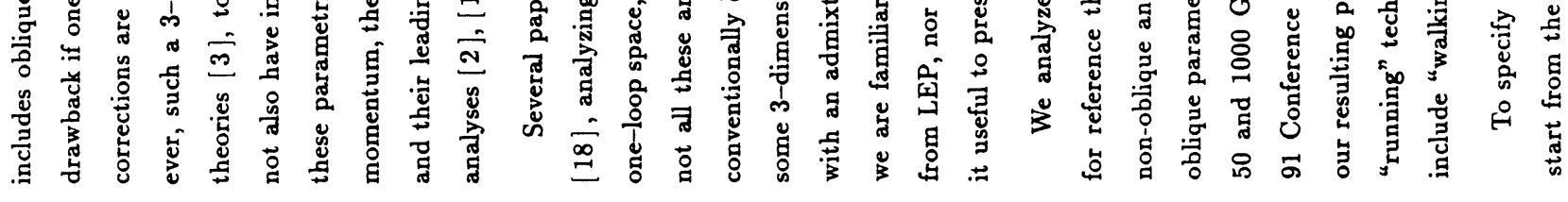

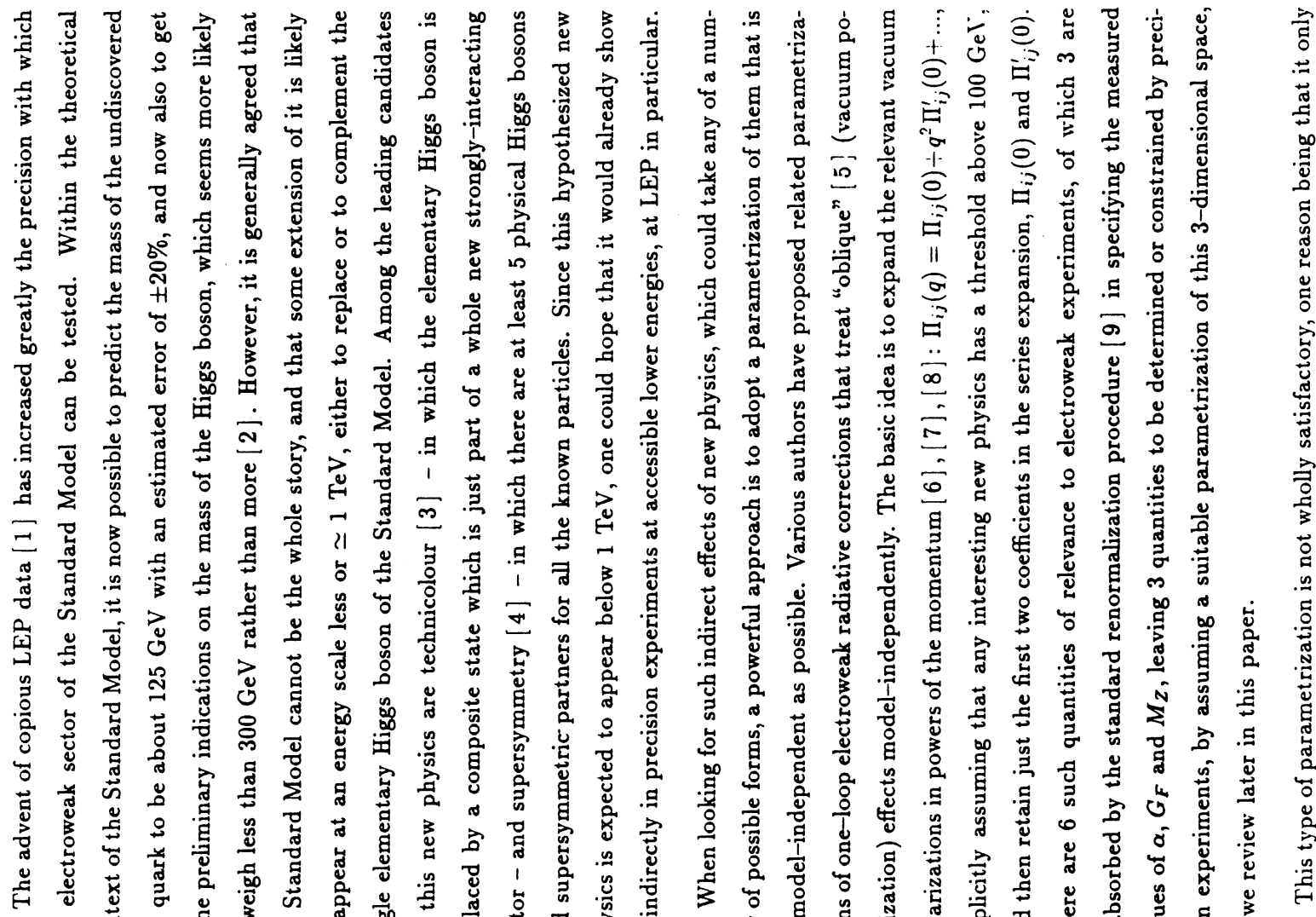

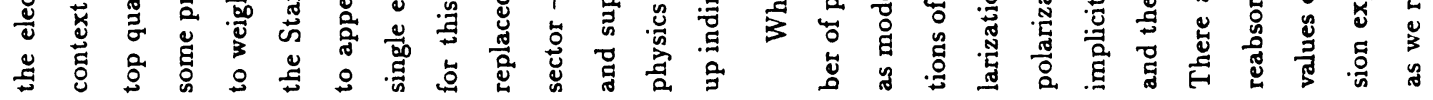




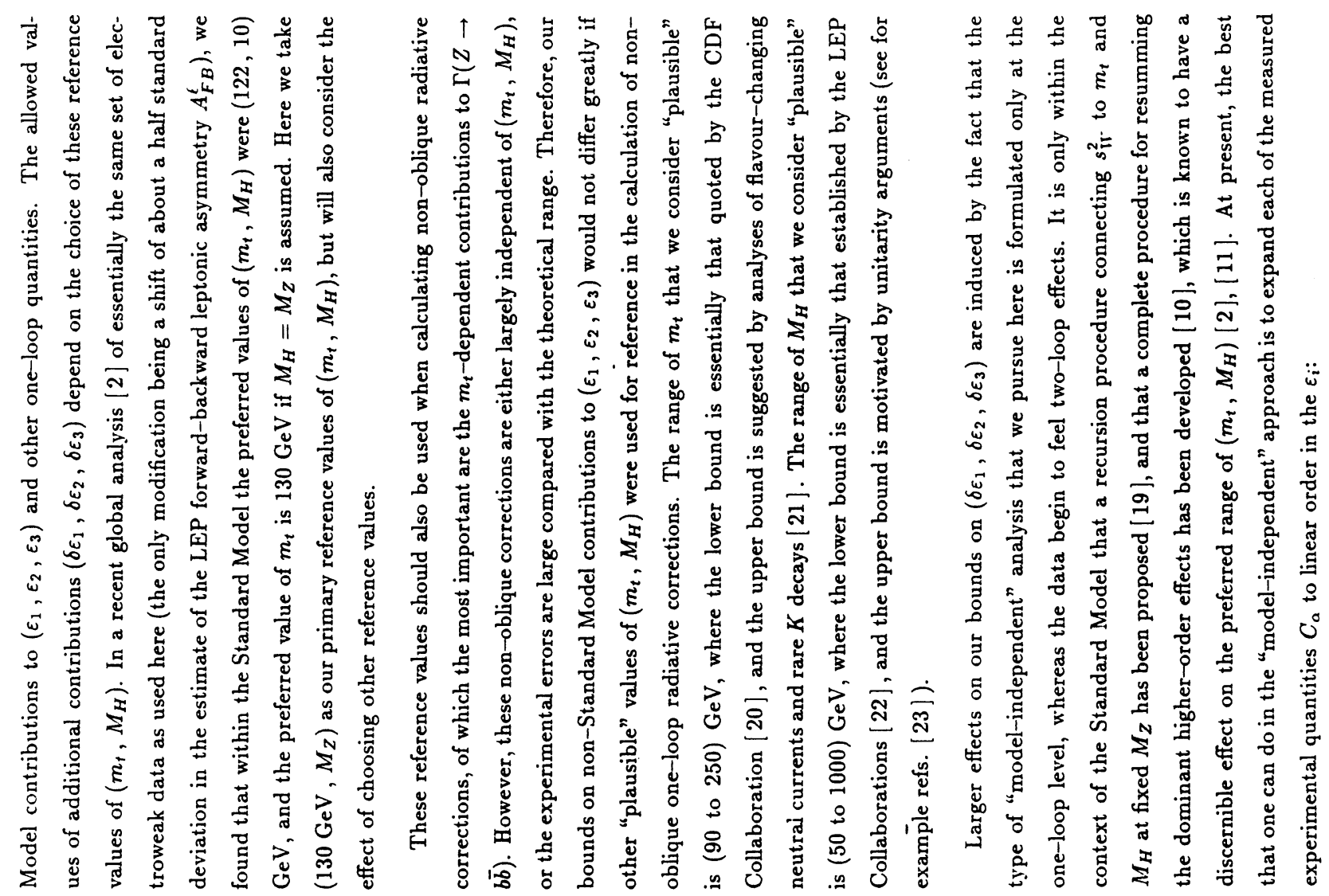

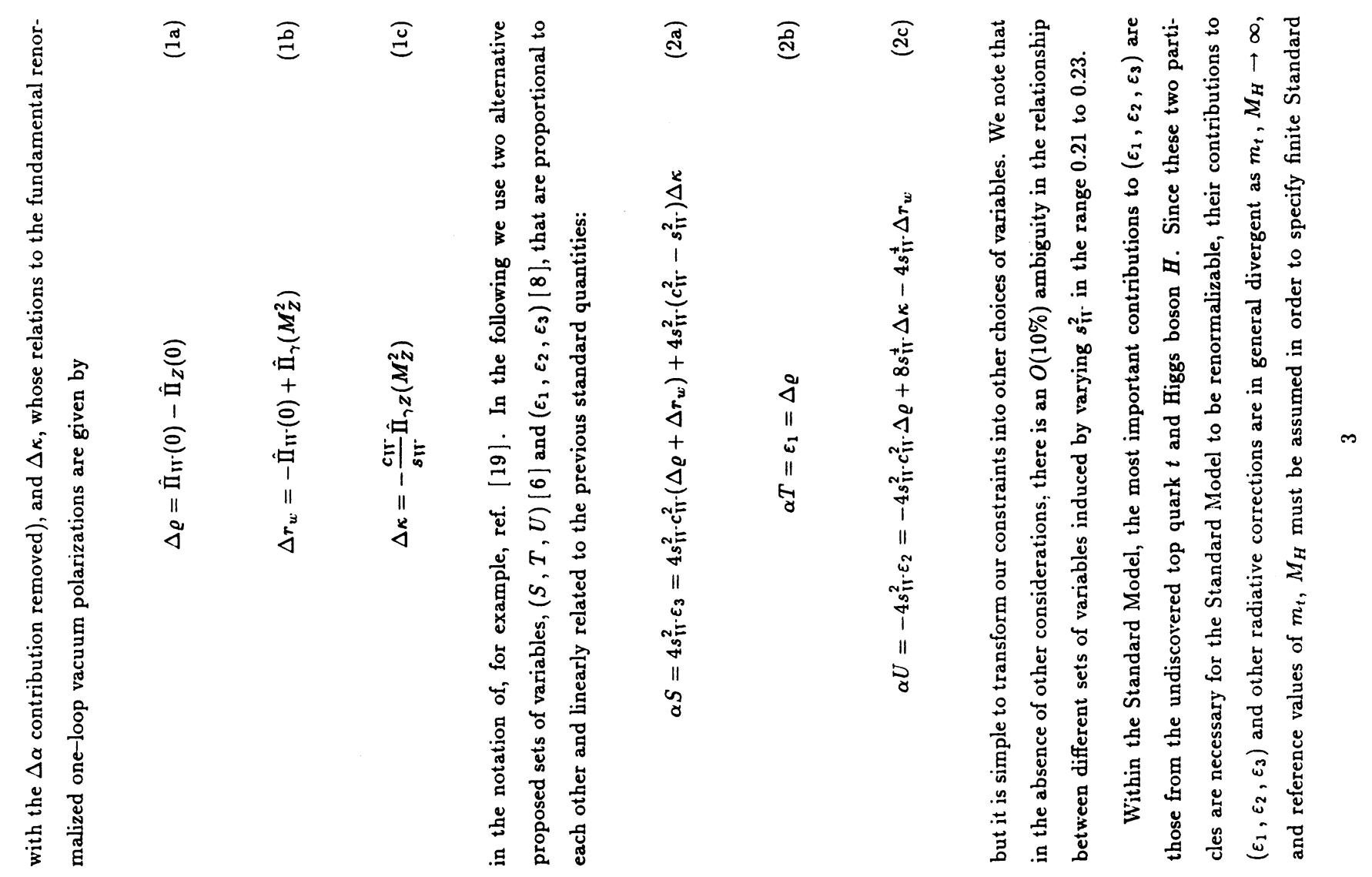



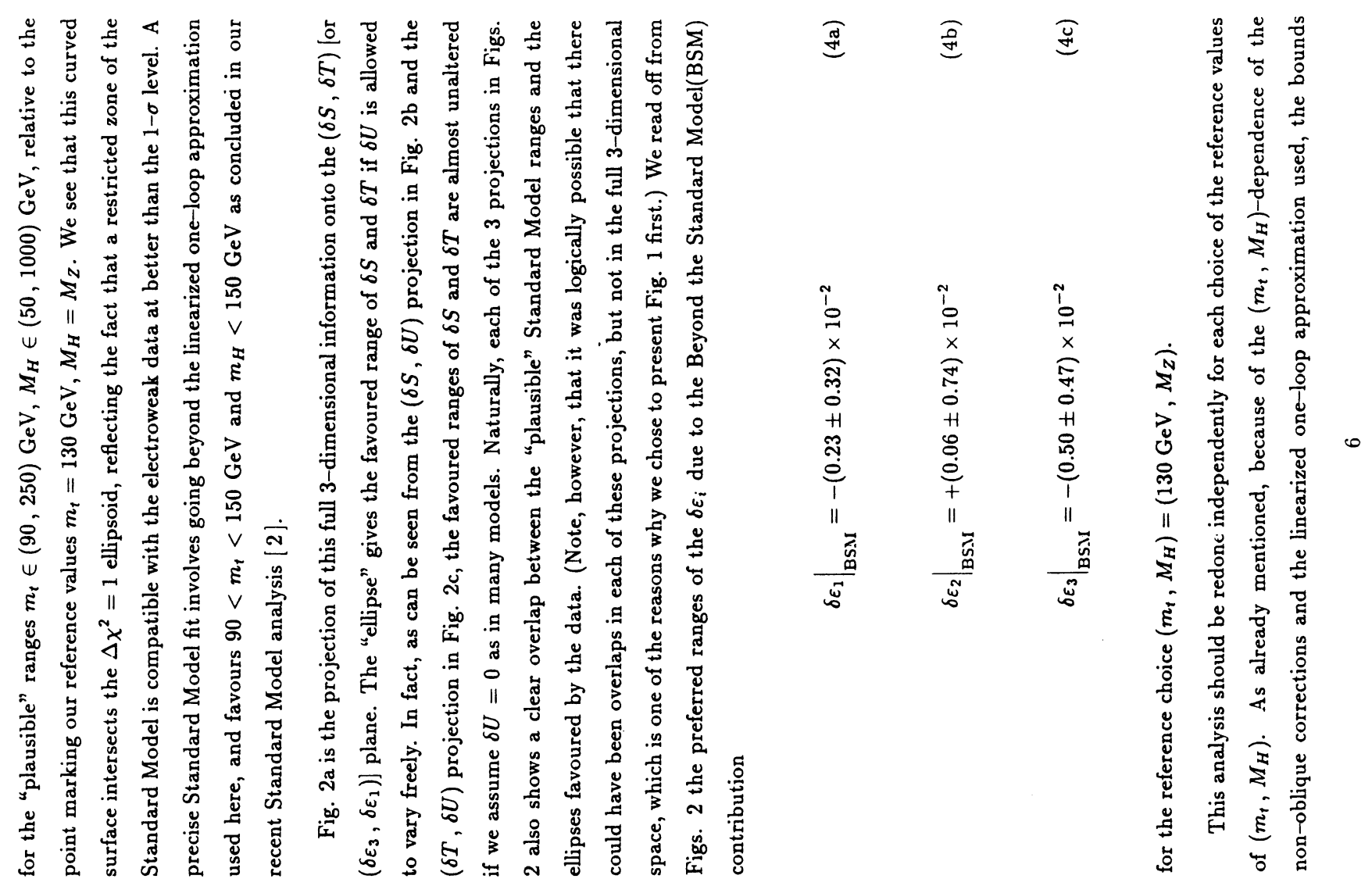

(2)

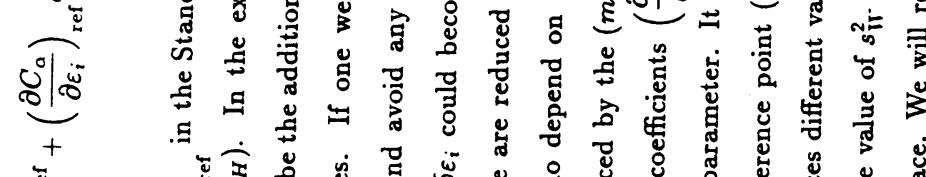
of

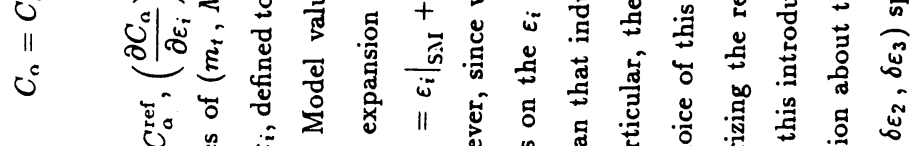
s. IIn III I I I I

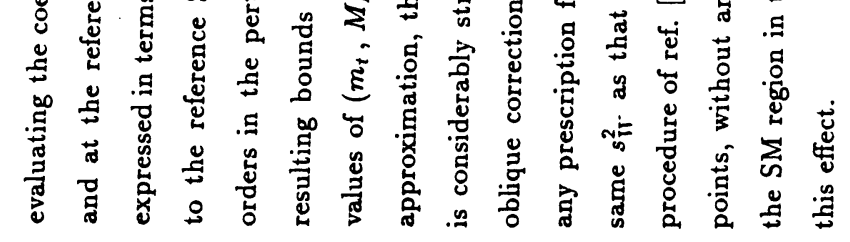

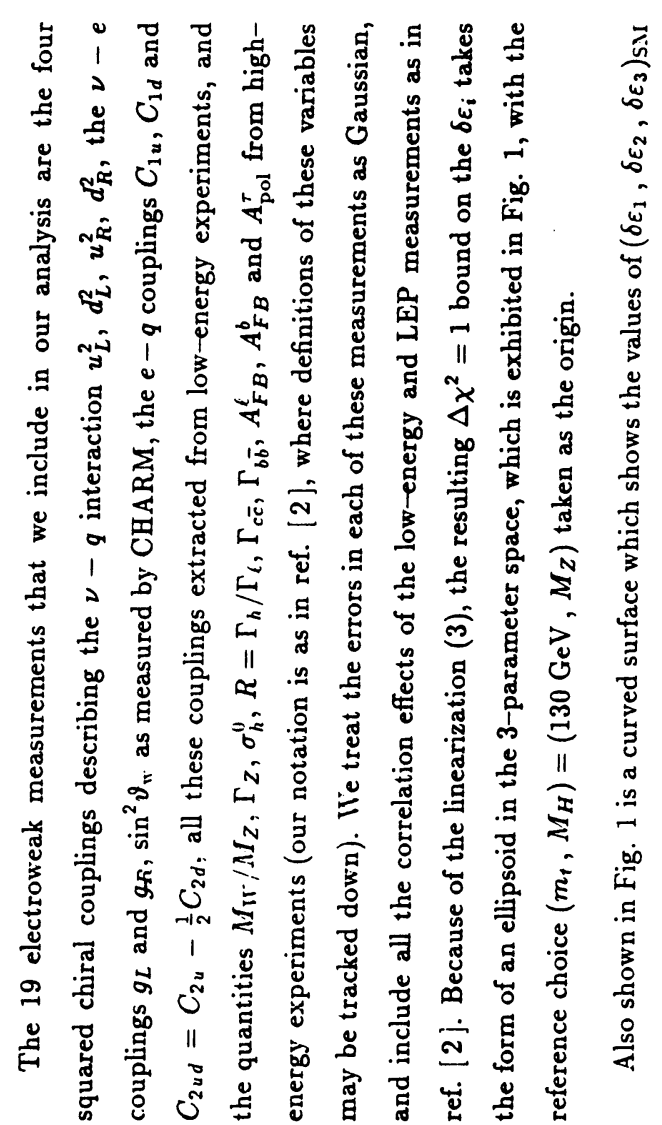




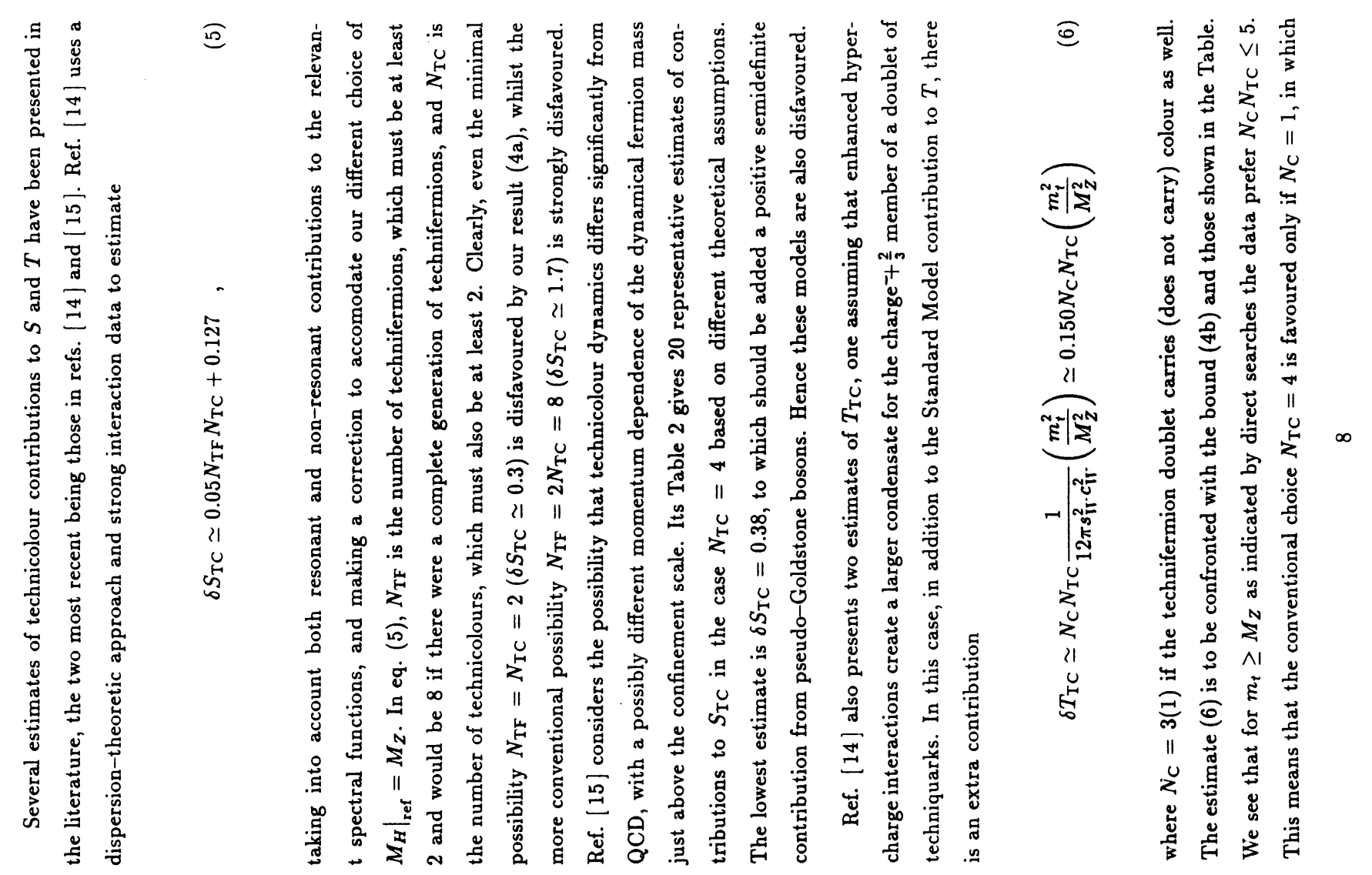

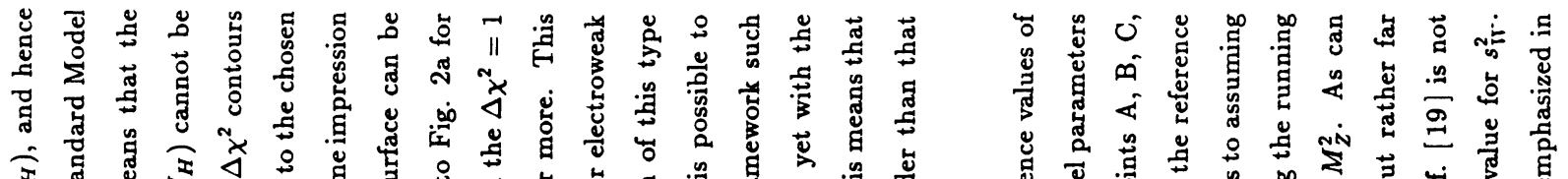

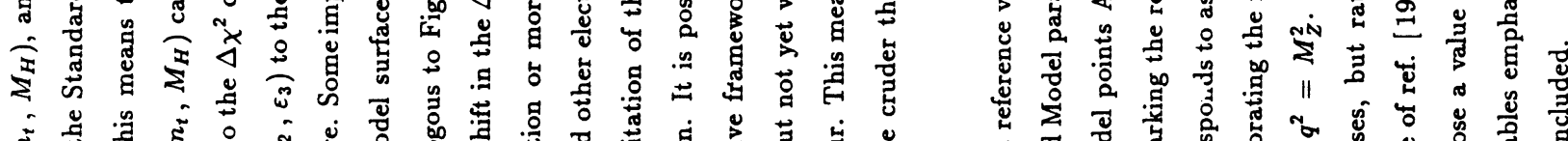

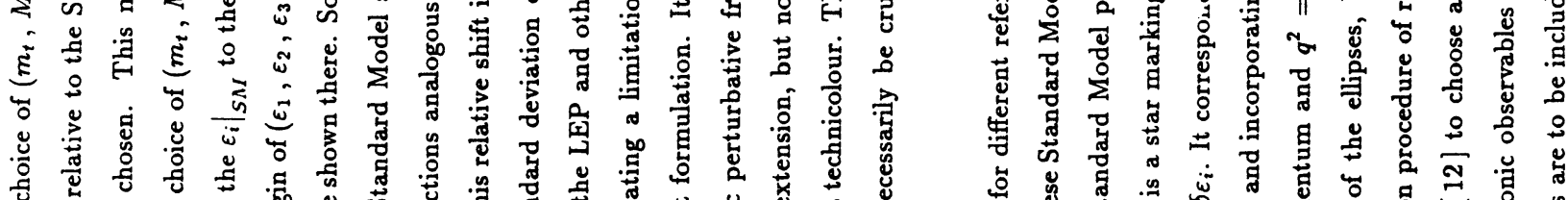

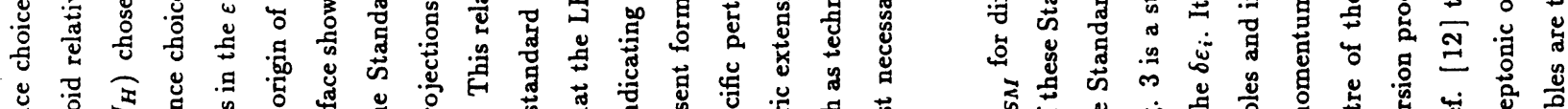

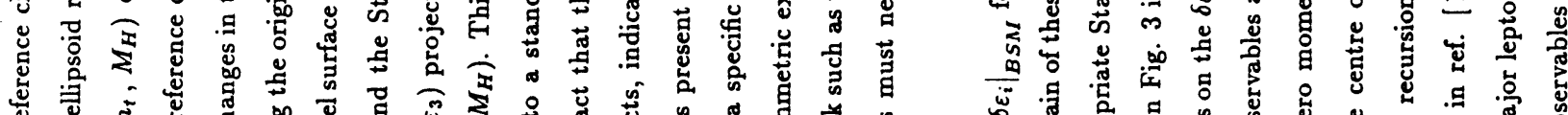

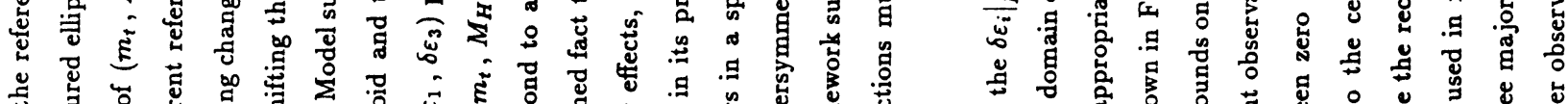

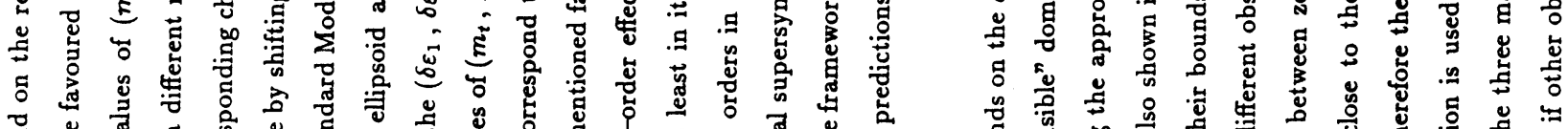

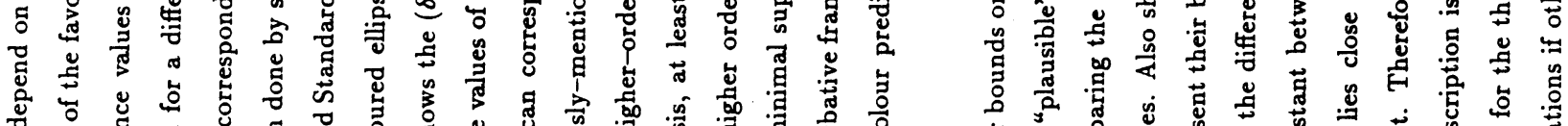

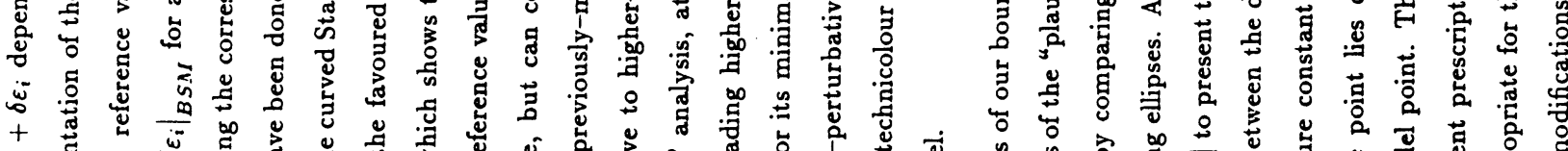

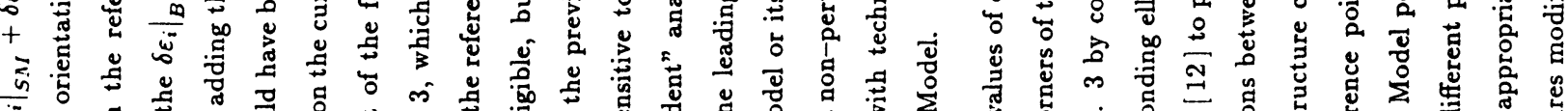

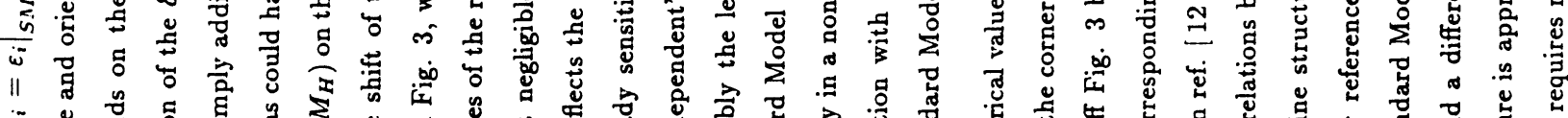

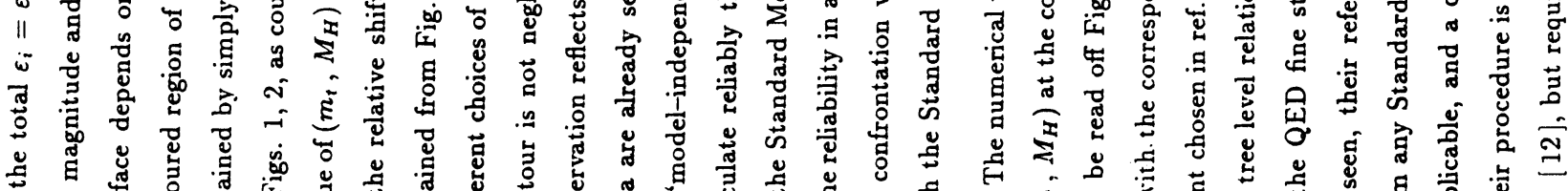

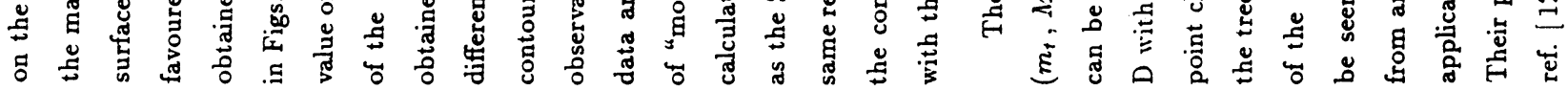



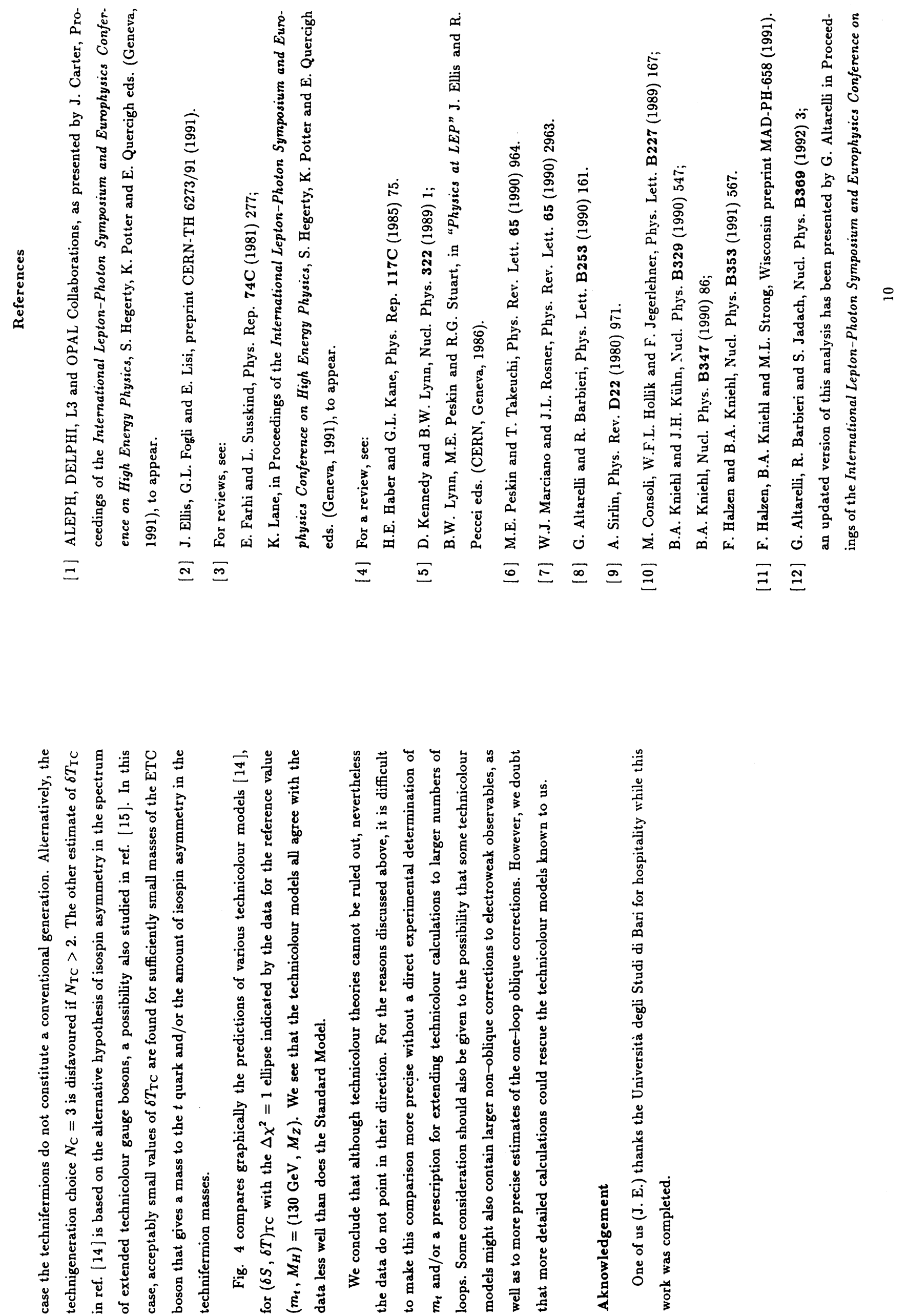

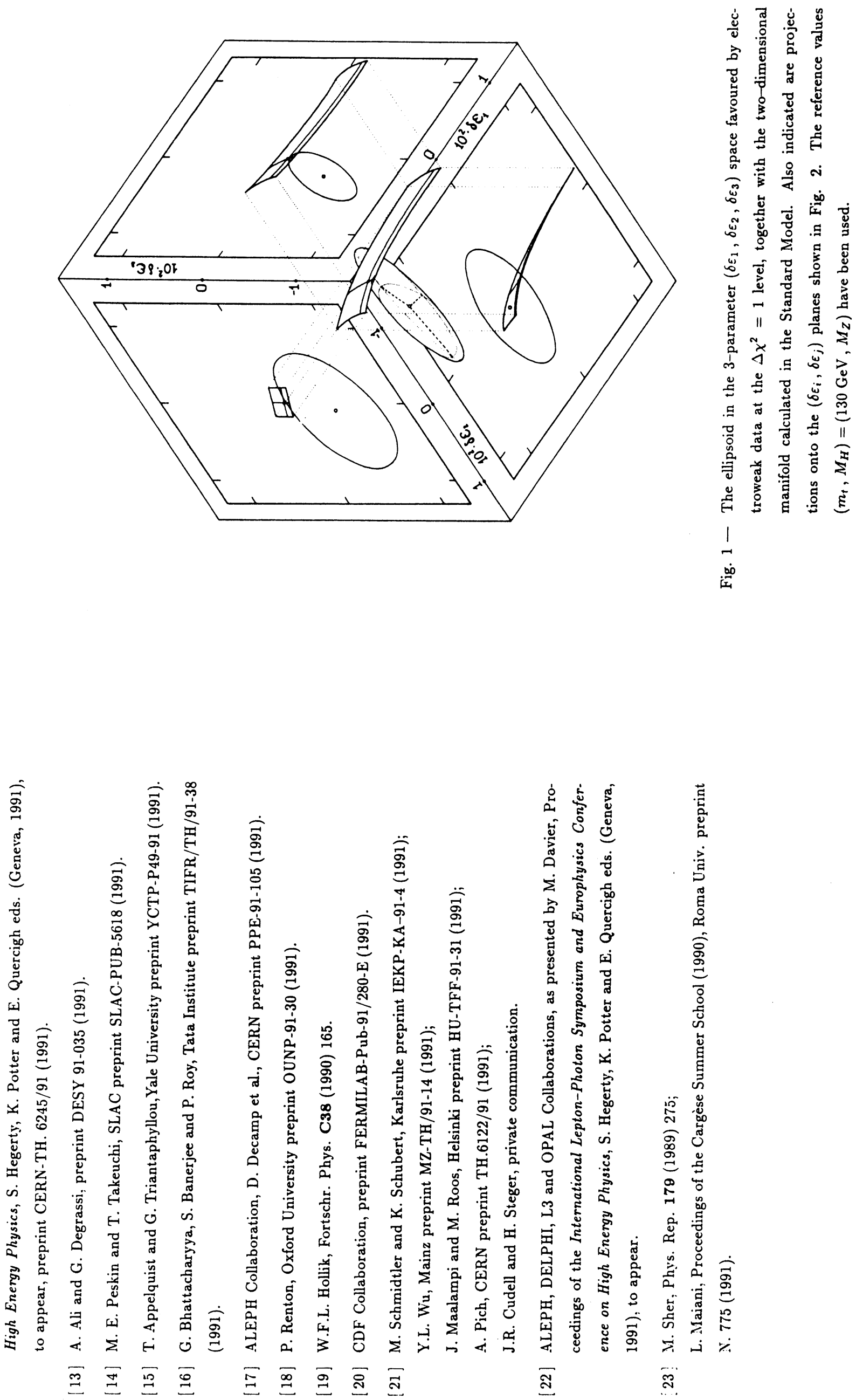

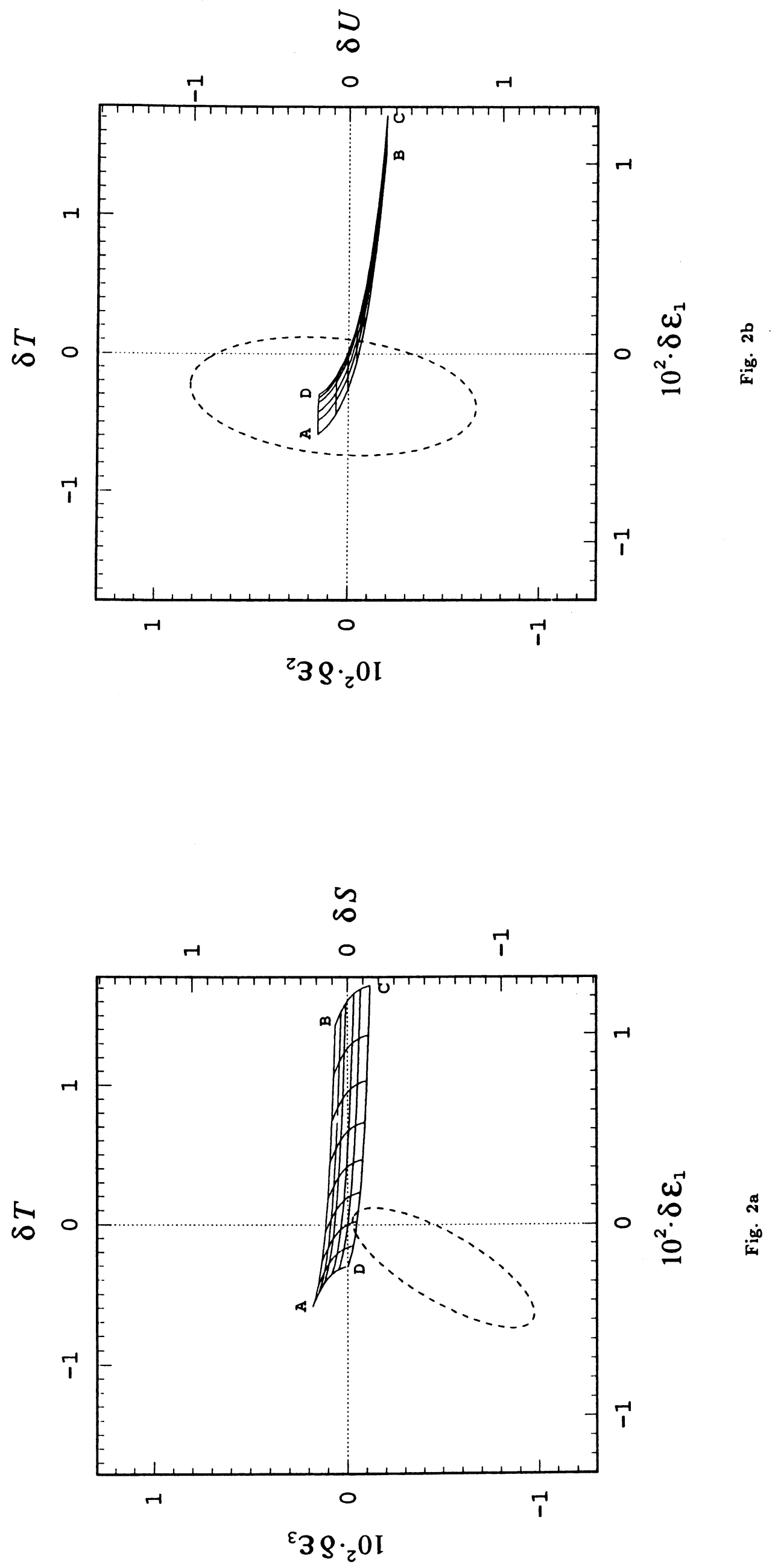

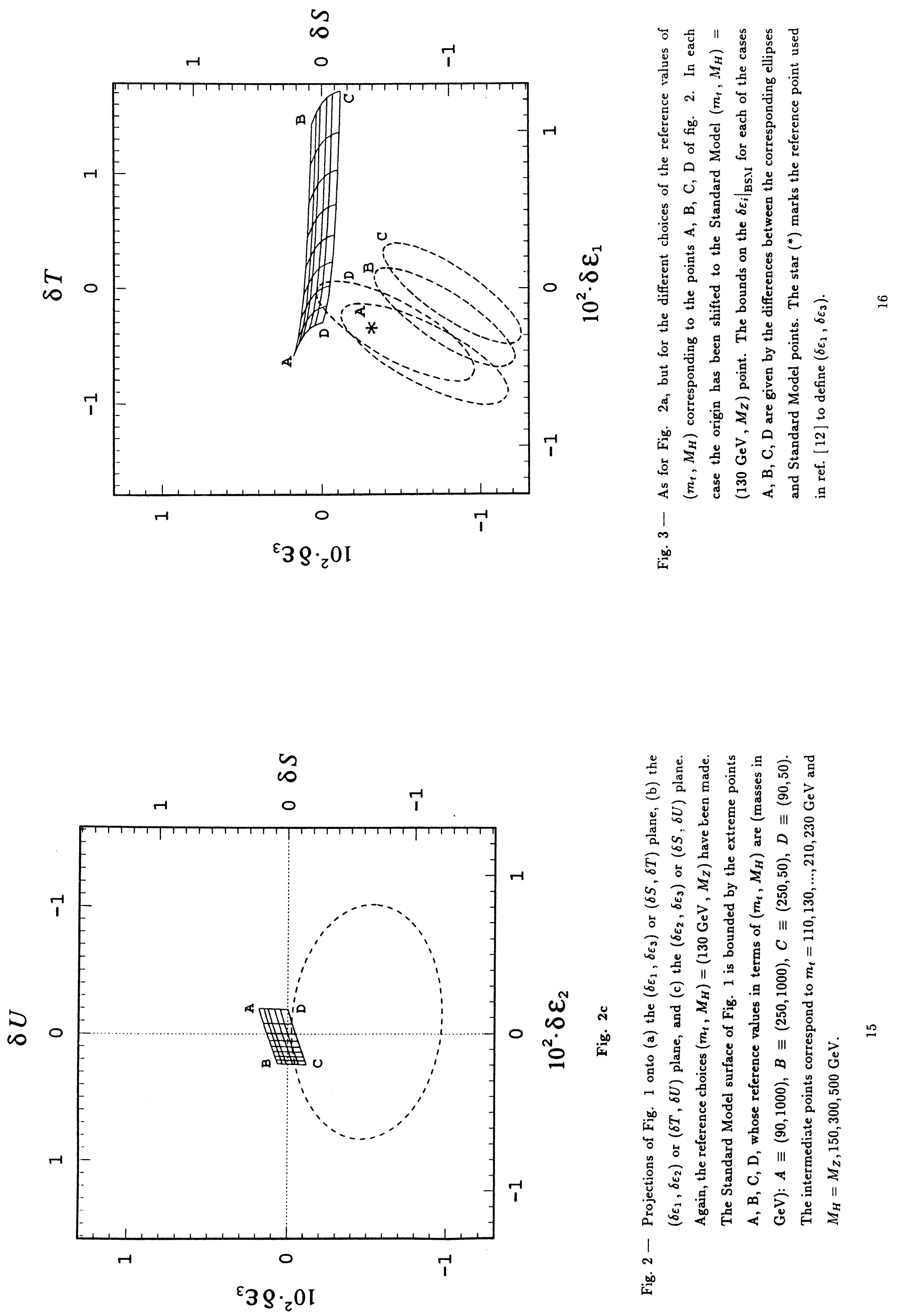


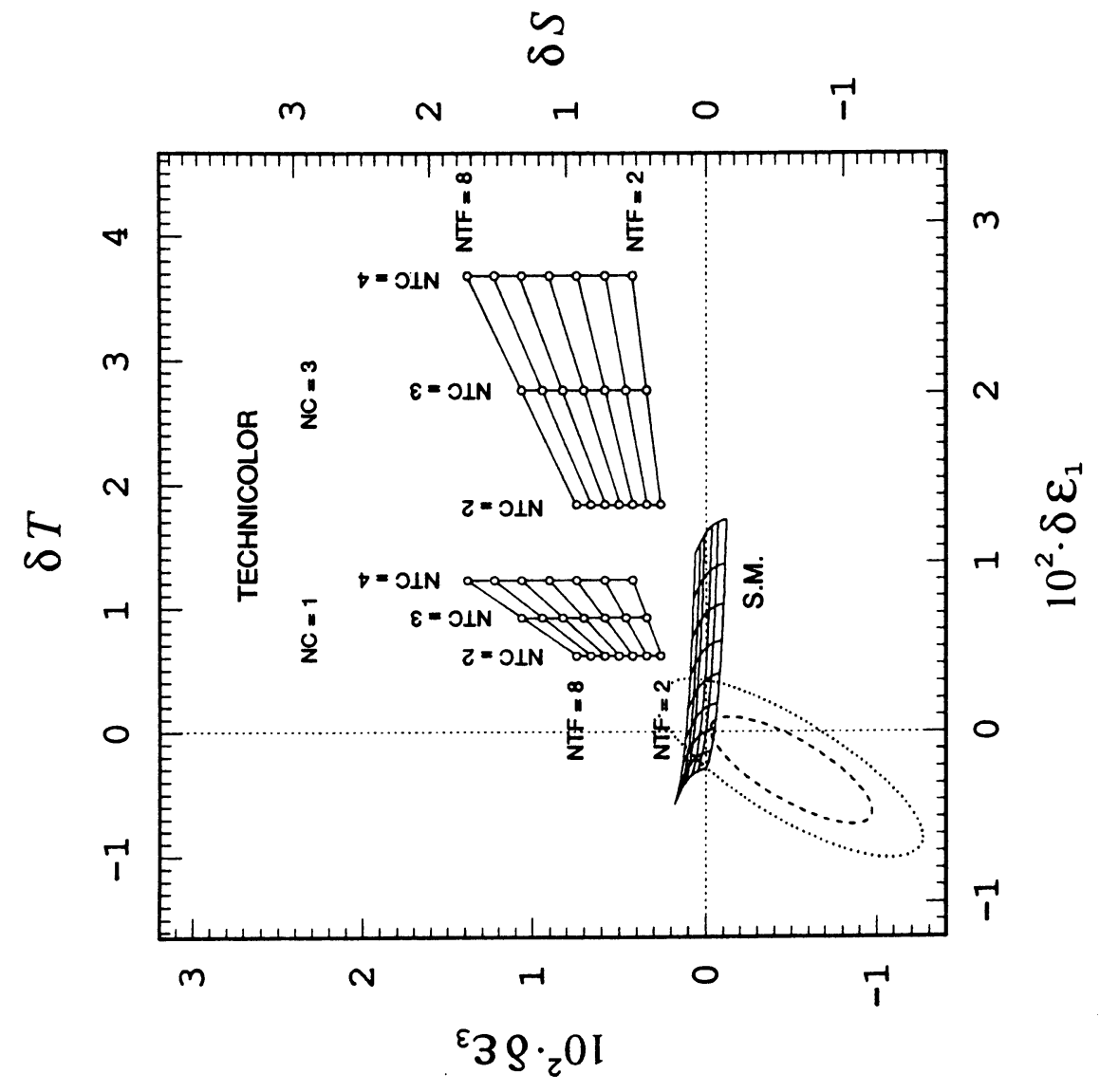

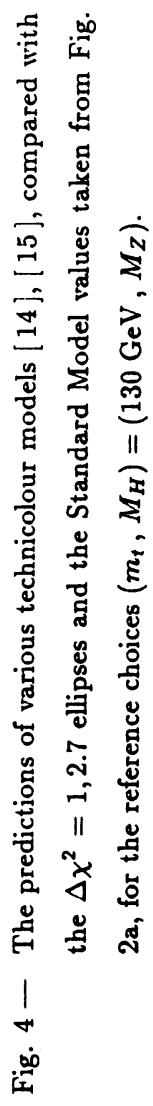

